\title{
Antigen-specific lymphocyte proliferation as a marker of immune response in guinea pigs with sustained Helicobacter pylori infection*
}

\author{
Eliza Miszczyk, Maria Walencka, Karolina Rudnicka, Agnieszka Matusiak, Wiesława Rudnicka \\ and Magdalena Chmiela
}

Department of Immunology and Infectious Biology, Institute of Microbiology, Biotechnology and Immunology, Faculty of Biology and Environmental Protection, University of Łódź, Łódź, Poland

\begin{abstract}
Helicobacter pylori (H. pylori) bacteria are human pathogens causing symptomatic gastritis, peptic ulcer or gastric cancer. Little is known about the kinetics of immune responses in $H$. pylori infected patients because the initial moment of infection has not been identified. Various animal models are used to investigate the immune processes related to $H$. pylori infection. In this study we checked whether $H$. pylori infection in guinea pigs, mimicking natural $H$. pylori infection in humans, resulted in the development of specific immune responses to $H$. pylori antigens by measuring the proliferation of lymphocytes localized in mesenteric lymph nodes, spleen and peripheral blood. The maturity of macrophages and cytokines, delivered by monocyte-macrophage lineage or lymphocytes, were considered as mediators, which might influence the lymphocyte blastogenic response. The obtained results showed the activation of T cells localized in mesenteric lymph nodes by $H$. pylori antigens in $H$. pylori infected guinea pigs four weeks postinfection. The blastogenic activity of lymphocytes was shaped by their interaction with antigen presenting cells, which were present in the cell cultures during the whole culture period. Moreover, the balance between cytokines derived from adherent leukocytes including interleukin 8 - IL-8 as well as interferon gamma - IFN- $\gamma$, and transforming growth factor beta - TGF- $\beta$ delivered by lymphocytes, was probably important for the successful proliferation of lymphocytes. The $H$. pylori specific lymphocytes were not propagated in peripheral blood and spleen of $H$. pylori infected animals. The modulation of immunocompetent cells by $\mathrm{H}$. pylori antigens or their different distribution cannot be excluded.
\end{abstract}

Key words: Helicobacter pylori, T cells, proliferation, guinea pigs

Received: 29 October, 2013; revised: 11 March, 2014; accepted: 31 March, 2014; available on-line: 13 June, 2014

\section{INTRODUCTION}

Persistent colonization of human gastric mucosa by Helicobacter pylori ( $H$. pylori) Gram-negative bacteria initiates a chronic gastritis (Warren \& Marshall, 1993). In about $80 \%$ of patients these bacteria do not cause clinical symptoms and the infection may persist for decades causing no harm to the host. Approximately $10-20 \%$ of infected individuals will suffer due to hyperacidity and may also develop gastric or duodenal ulcers. About 1\% of infected patients will devolop gastric cancer. These complications depend on the $H$. pylori strain but also on the individual susceptibility to infection related to immune responses against $H$. pylori pathogens (PortalCelhay \& Perez-Perez, 2006). Clinical manifestation of H. pylori infections results from multiple gastrointestinal responses to various bacterial products, including the reactions of both epithelial cells and the cells of immune system. However, the nature and the consequences of interactions between $H$. pylori factors, and host cells promoting persistent colonization are not well understood. $H$. pylori infections result in a $\mathrm{T}$ helper 1 (Th1) predominant host immune response in the gastric mucosa, which is characterized by the induction of interferon gamma $(\mathrm{IFN}-\gamma)$ and elevated levels of other proinflammatory cytokines such as interleukin 12 (IL-12), IL-18 and tumor necrosis factor alpha (TNF- $\alpha$ ) (Tummala et al., 2004). The immune and inflammatory responses in $H$. pylori infected subjects are also related to IL-1 $\beta$ production. This cytokine is a powerful inhibitor of gastric acid secretion, which is crucial for amplifying the inflammatory response to $H$. pylori infection (Noach et al., 1994), and plays an important role as a $\mathrm{T}$ cell signalling molecule.

The priming of the immune response to $H$. pylori may take place in lamina propria, infiltrated by antigen presenting cells, monocytes, macrophages and dendritic cells. Gastric epithelial cells, which up-regulate the expression of the major histocompatibility complex (MHC) class II and costimulatory molecules during $H$. pylori infection, may enhance antigen presentation. Alternatively, immune priming may occur within lymph nodes draining the stomach, or at intestinal sites, in response to $H$. py-

e-mail: chmiela@biol.uni.lodz.pl

*The preliminary report on the same subject was presented at MIKROBIOT 2013 Workshop, Łódź, Poland

Abbreviations: APAAP, alkaline phosphatase - anti-alkaline phosphatase; CFU, colony forming units; CRPMI, complete RPMI-1640 culture medium; CagA, cytotoxin associated gene A antigen; dGE, denatured glycine acid extract; DMSO, dimethyl sulfoxide; EDTA, ethylenediaminetetraacteic acid; FCS, fetal calf serum; FITC, fluorescein isothiocyanate; GE, glycine acid extract; $H$. pylori, Helicobacter pylori; HLO, Helicobacter-like organisms; IFN- $\gamma$, interferon gamma; IL, interleukin; LPS, lipopolysaccharide; MHC, major histocompatibility complex; nGE, native glycine acid extract; TNF-a, tumor necrosis factor alpha; PRR, pathogen recognition receptors; PBS, phosphate buffered saline; PHA, phytohaemagglutinin; RT-PCR, reverse transcription polymerase chain reaction; $\mathrm{NaCl}$, sodium chloride; SD, standard deviation; SI, stimulation index; Th1, T helper 1 ; tMLNL, total mesenteric lymph node leukocytes; tPBML, total peripheral blood mononuclear leukocytes; TBS, Tris-buffered saline; TGF- $\beta$, transforming growth factor beta; VacA, vacuolating cytotoxin. 
lori antigens and intact organisms that are shed from the stomach surface (Algood \& Cover, 2006).

To a certain degree, the outcome of $H$. pylori infections depends on the ability of the cells to proliferate in response to $H$. pylori antigens. A number of $H$. pylori compounds appear to reduce recognition of $H$. pylori antigens by the host immune cells, or affect their viability, by the induction of apoptosis or cell cycle arrest. It was shown that negative immunomodulatory activity could be related to the $H$. pylori vacuolating cytotoxin ( $\mathrm{VacA}$ ), the cytotoxin associated gene A (CagA) antigen, and the lipopolysaccharide (LPS) (Paziak-Domanska et al., 2000; Sundrud et al., 2004; Torres et al., 2007; Grębowska et al., 2010). In humans, the inhibition of lymphocyte blastogenic response, in the milieu of $H$. pylori antigens, could be followed by diminished expansion of antigen specific $\mathrm{T}$ lymphocytes, and thus, ineffective elimination of these pathogens (Paziak-Domańska et al., 2000; Grębowska et al., 2010). If so, the ability of the immune cells to respond to $H$. pylori antigens by proliferation could be an important marker of the development of specific immune responses to ongoing infection, and distribution of antigen-specific lymphocytes. It can allow predicting an effector potential of immunocompetent cells.

The condition of macrophages and dendritic cells, as antigen presenting cells, infiltrating the inflammatory milieu in lamina propria, or in mesenteric lymph nodes, is important for successful recognition of $H$. pylori antigens by $\mathrm{T}$ and $\mathrm{B}$ lymphocytes. This process is influenced by various soluble mediators, mainly cytokines. Little is known about the kinetics of immune responses in patients infected with $H$. pylori because the moment of initiation of infection has not been identified. Various animal models are used to test the immune processes related to $H$. pylori infections. In this study we checked whether oral infection of guinea pigs with $H$. pylori, mimicking natural $H$. pylori infection in humans, resulted in the development of specific immune responses to $H$. pylori antigens by measuring the proliferation of mesenteric lymph nodes, spleen and peripheral blood lymphocytes. The maturity of macrophages and the milieu of cytokines delivered by the cells of monocyte-macrophage lineage such as IL-1 $\beta$ and IL- 8 or by the lymphocytes: IFN $-\gamma$ and transforming growth factor beta - TGF- $\beta$

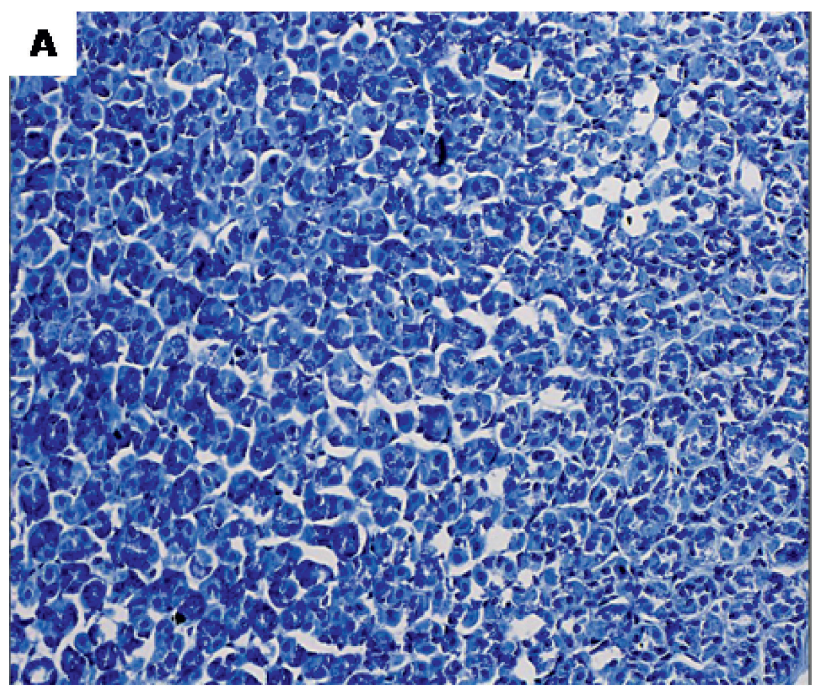

were taken into consideration as important factors, which might influence the lymphocyte blastogenic response.

\section{MATERIALS AND METHODS}

Animals. For the experiments, adult, three-monthold, 400-600 g of weight male Himalayan guinea pigs were used. Animals were bred in the Animal House of the University of Lódź, (Poland), kept in cages with free access to drinking water and fed with standard chow. All animal experiments were approved by the Local Ethics Committee LKB9 (Decision LB 646/2012).

Bacteria. Helicobacter pylori reference strain CCUG 17874, positive for VacA and CagA was obtained from the Culture Collection, University of Gothenburg (Gothenburg, Sweden). H. pylori bacteria were stored at $-80^{\circ} \mathrm{C}$ in Tris-buffered saline (TBS) containing $10 \%$ glycerol. Before being used in the experiments $H$. pylori bacteria were grown for 5 days on modified Helicobacter agar (Becton Dickinson, Heidelberg, Germany) in microaerophilic conditions (Gas Pak, Becton Dickinson, Heidelberg, Germany), at $37^{\circ} \mathrm{C}$. The bacteria were harvested by scraping from agar plates, suspended in $0.85 \%$ sodium chloride $(\mathrm{NaCl})$, pelleted by centrifugation $(4000 \times g$, for $15 \mathrm{~min}$ ), and then washed twice under the same conditions. The pellet of bacteria was suspended in $0.85 \%$ $\mathrm{NaCl}$ to obtain the inoculum containing $1 \times 10^{10}$ colony forming units - $\mathrm{CFU} / \mathrm{ml}$ according to the McFarland scale.

H. pylori glycine acid extract (GE). Surface $H$. $p y$ lori antigens were extracted from the reference $H$. pylori strain CCUG 17874 using $0.2 \mathrm{M}$ glycine buffer, $\mathrm{pH} 2.2$, as previously described (Rechciński et al., 1997). The protein content in GE was 98.4\% (NanoDrop 2000c Spectrophotometer, ThermoScientific, Wlatman, WY, USA). For experiments native GE (nGE) was used, as well as GE denaturated by heating for $30 \mathrm{~min}$, at $80^{\circ} \mathrm{C}$ (dGE). The GE antigens were used for a further study in a protein concentration of $5 \mu \mathrm{g} / \mathrm{ml}$.

Inoculation of guinea pigs with $\boldsymbol{H}$. pylori. The animals (8) were divided into two groups. Group 1 consisted of 4 guinea pigs, which were inoculated per os three times (at two-day intervals) with $1 \mathrm{ml}$ of sterile $0.85 \%$ $\mathrm{NaCl}$, using a feeding needle (control group). Group 2

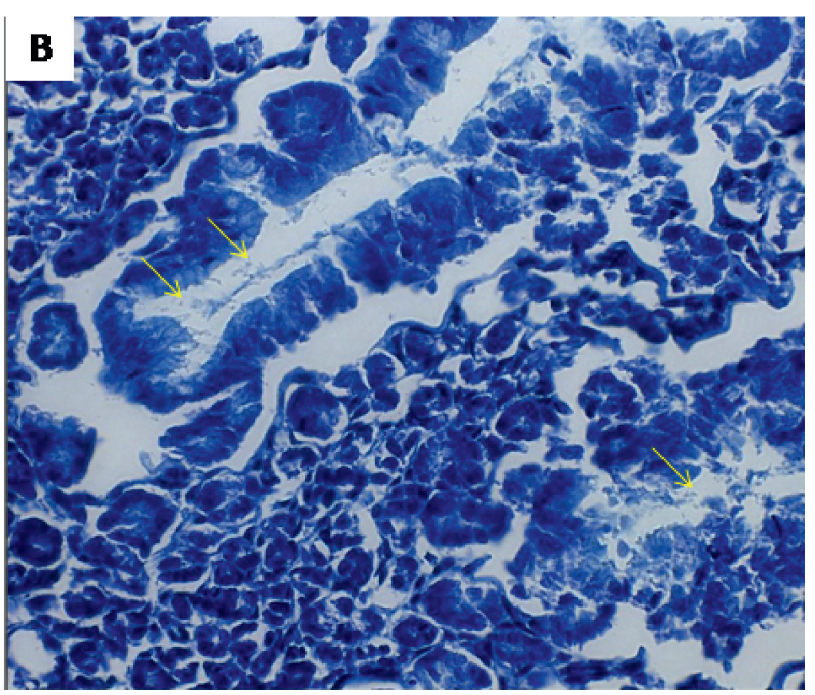

Figure 1. Detection of $H$. pylori in the gastric tissues of guinea pigs.

Giemsa stained thin layer sections of the stomach tissue from H. pylori uninfected (A) or H. pylori infected animals (B) were analysed using light microscope. Arrows indicate a lumen gland filled with spiral shaped bacteria - Helicobacter-like organisms. (A) magnification, x100, (B) magnification, x1000. 

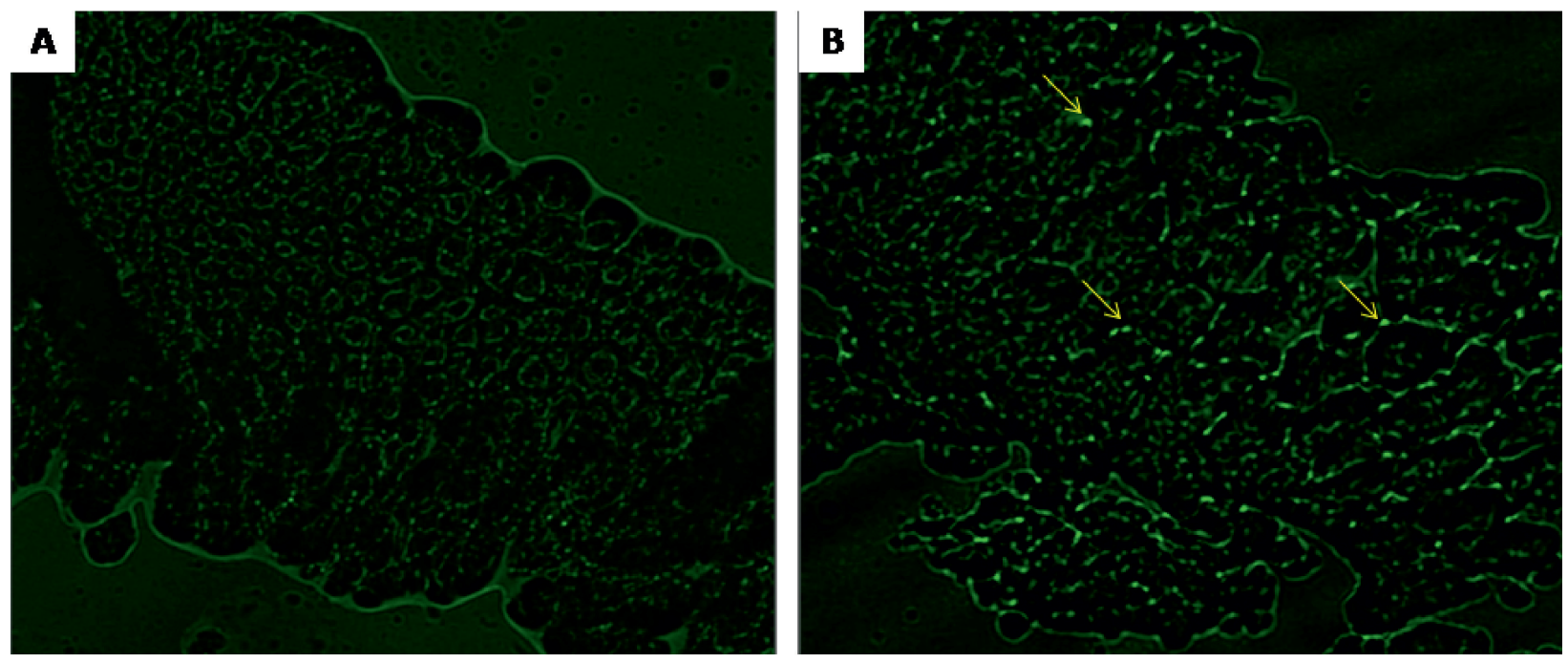

Figure 2. Detection of $H$. pylori in the smears of gastric mucosa from $H$. pylori uninfected (A) or H. pylori infected (B) guinea pigs. Rabbit polyclonal anti-H. pylori antibodies FITC-conjugated were used for staining of bacteria. The cell imaging was performed using the JuLI Smart fluorescent cell analyzer (Digital Biotechnology, Boston, USA). Arrows indicate the localization of H. pylori rods (magnification, $\mathrm{x} 1000)$.

consisted of 4 animals, which were orally inoculated, three times (at two-day intervals), with $1 \mathrm{ml}$ of freshly prepared suspension of $H$. pylori $\left(10^{10} \mathrm{CFU} / \mathrm{ml}\right)$. Before administration of $\mathrm{NaCl}$ or $\mathrm{H}$. pylori, the animals were given orally $1 \mathrm{ml}$ of $0.2 \mathrm{~N} \mathrm{NaHCO}$ to quickly neutralize the acidic $\mathrm{pH}$ of the stomach. Guinea pigs of both groups were euthanized 4 weeks after the last challenge, using diethyl ether narcosis. Peripheral blood and mesenteric lymph nodes were collected for isolation of leukocytes. The $H$. pylori infection in the guinea pigs was confirmed by detection of Helicobacter-like organisms (HLO) in thin layer sections of the stomach tissue, which were stained by routine histological procedure with the Giemsa stain solution and analysed according to the Sydney scale using light microscope (Fig. 1). Moreover, the presence of $H$. pylori in the gastric mucosa was confirmed by staining of mucus smears with rabbit anti- $H$. pylori antibodies conjugated with fluorescein isothiocyanate (FITC) (Fig. 2). The cell imaging was performed using JuLI Smart fluorescent cell analyzer (Digital Biotechnology, Boston, USA).

Total peripheral blood mononuclear leukocytes (tPBML). Peripheral blood was collected on EDTA as an anticoagulant. Mononuclear leukocytes were separated by Histopaque 1077 gradient centrifugation (Sigma St. Louis, MI, USA), and washed twice by centrifugation $(300 \times \mathrm{g}, 10 \mathrm{~min})$ with complete RPMI-1640 culture medium (cRPMI) containing 10\% heat-inactivated fetal calf serum, $200 \mathrm{mM}$ L-glutamine, 100 units $/ \mathrm{ml}$ of penicillin and $100 \mu \mathrm{g} / \mathrm{ml}$ of streptomycin. The cell suspensions were adjusted to the density of $5 \times 10^{6} \mathrm{cells} / \mathrm{ml}$ and used in single stage proliferation assay. The cell viability estimated by trypan blue exclusion was $>90 \%$.

Total mesenteric lymph node leukocytes (tMLNL). Mesenteric lymph nodes were removed from euthanized guinea pigs and homogenized in cRPMI. Homogenates were centrifuged at $300 \times g$, for $10 \mathrm{~min}$, and washed twice. The cell pellets were suspended in cRPMI medium, adjusted to the density of $5 \times 10^{6}$ cells $/ \mathrm{ml}$, evaluated in terms of cell viability by trypan blue exclusion $(>90 \%)$, and used in a single stage proliferation assay.

Spleen lymphocytes. Isolated spleens were homogenized, and splenocytes were washed in cRPMI by cen- trifugation $\left(300 \times g, 10 \mathrm{~min}, 20^{\circ} \mathrm{C}\right)$. The erythrocytes were lysed using a lysis buffer, and the remaining leukocytes were recovered by centrifugation. The cell viability was assessed by trypan blue exclusion, and the suspensions of splenocytes in a density of $1 \times 10^{8}$ cells $/ \mathrm{ml}$ in cRPMI were prepared. Spleen cells were enriched with T lymphocytes by passing of the splenocyte suspensions, in a volume of $1 \mathrm{ml}\left(1 \times 10^{8}\right.$ cells $\left./ \mathrm{ml}\right)$, through nylon wool fiber columns $\left(45 \mathrm{~min}\right.$, at $\left.37^{\circ} \mathrm{C}, 5 \% \mathrm{CO}_{2}\right)$. The nonadherent $\mathrm{T}$ lymphocytes were washed out of the column with cRPMI, assessed for viability, which was $>90 \%$, and adjusted to the density of $2.5 \times 10^{6}$ cells $/ \mathrm{ml}$ in cRPMI. For two-stage mixed cultures of spleen lymphocytes with mature bone marrow macrophages, the spleen cells were frozen in FCS $/ 10 \%$ DMSO for $96 \mathrm{~h}$, at $-80^{\circ} \mathrm{C}$. Before being used in cell culture experiments, the splenic lymphocytes were thawed and adjusted to the density of $2.5 \times 10^{6}$ viable cells $/ \mathrm{ml}$ in cRPMI.

Bone marrow-derived macrophages. Bone marrow macrophages were isolated to cRPMI medium from tibias and femurs, washed twice, and pelleted by centrifugation. The bone marrow cells were suspended in $1 \mathrm{ml}$ of cRPMI and attached to the cell culture Petri dishes for $1 \mathrm{~h}, 37^{\circ} \mathrm{C}, 5 \% \mathrm{CO}_{2}$. Non-adherent cells were washed out, and non mature macrophages were detached for $10 \mathrm{~min}, 37^{\circ} \mathrm{C}, 5 \% \mathrm{CO}_{2}$, with phosphate buffered saline (PBS) without $\mathrm{Ca}^{2+}$ and $\mathrm{Mg}^{2+}$, containing $0.5 \mathrm{mM}$ EDTA. After washing twice, fresh macrophages were adjusted to the density of $5 \times 10^{5}$ cells $/ \mathrm{ml}$ in cRPMI and used for further experiments. For some experiments, adherent fresh macrophages, in $200 \mu \mathrm{l}$ of cRPMI/well, were allowed to mature for 5 days with half a volume of cRPMI exchange on the $3^{\text {rd }}$ day of the incubation time.

Single-stage cultures of tPBML or tMLNL. The tPBML or tMLNL $\left(5 \times 10^{6}\right.$ cells $\left./ \mathrm{ml}\right)$ whole leukocyte populations, which were distributed in 96-well microplates $(100 \mu \mathrm{l} /$ well $)$, were stimulated for $72 \mathrm{~h}\left(37^{\circ} \mathrm{C}, 5 \%\right.$ $\mathrm{CO}_{2}$ ) with $5 \mu \mathrm{g} / \mathrm{ml}$ of $H$. pylori $\mathrm{GE}$, $\mathrm{nGE}$ or $\mathrm{dGE}$, or $2 \mu \mathrm{g} / \mathrm{ml}$ phytohaemagglutinin - PHA (Sigma, St. Louis, USA), as a positive control for the lymphocyte proliferation. The experiments were performed in triplicate in cRPMI medium. In some experiments the modulation of PHA-driven proliferation of lymphocytes by $H$. $p y$ - 
lori GE antigens was investigated. For this purpose the tMLNL $\left(5 \times 10^{6}\right.$ cells $\left./ \mathrm{ml}\right)$ population was cultured for $72 \mathrm{~h}$ with no stimuli PHA alone or with PHA $(2 \mu \mathrm{g} / \mathrm{ml})$ and a bacterial stimulant: $H$. pylori nGE or dGE $(5 \mu \mathrm{g} /$ $\mathrm{ml})$. At $18 \mathrm{~h}$ before the end of culture, $1 \mu \mathrm{Ci}$ of $\left[{ }^{3} \mathrm{H}\right]-$ thymidine was added to each well to estimate cell proliferation. All cell cultures were settled in triplicate.

Two-stage mixed cultures of immature or mature bone marrow macrophages with autologous spleen lymphocytes. Two-stage cultures containing immature bone marrow macrophages and autologous $T$ lymphocytes from the spleen were prepared according to the following procedure: the immature macrophages $\left(5 \times 10^{5}\right.$ cells $/ \mathrm{ml})$, distributed into 96 well plates $(100 \mu \mathrm{l} /$ well $)$ were stimulated for $2 \mathrm{~h}\left(37^{\circ} \mathrm{C}, 5 \% \mathrm{CO}_{2}\right)$ with $5 \mu \mathrm{g} / \mathrm{ml}$ of $\mathrm{nGE}$ or $\mathrm{dGE}$, or left unstimulated (cRPMI alone). The stimuli were washed out from immature macrophages and supplemented with freshly isolated autologous spleen $\mathrm{T}$ lymphocytes $\left(2.5 \times 10^{6} \mathrm{cells} / \mathrm{ml}\right)$ in the ratio of 1:5. The cultures were supplemented with $100 \mu \mathrm{l}$ of cRPMI or $2 \mu \mathrm{g} / \mathrm{ml}$ PHA and incubated for further $72 \mathrm{~h}$, at $37^{\circ} \mathrm{C}, 5 \% \mathrm{CO}_{2}$. At $18 \mathrm{~h}$ before the end of culture, $1 \mu \mathrm{Ci}$ of $\left[{ }^{3} \mathrm{H}\right]$-thymidine was added to each well to estimate cell proliferation. The preparation of two-stage cultures of mature bone marrow macrophages and autologous $\mathrm{T}$ lymphocytes isolated from the spleen involved two stages. First, the monolayers of mature macrophages (incubated for 5 days in cRPMI with addition of $50 \mathrm{nM}$ $\beta$-mercaptoethanol, $\left.37^{\circ} \mathrm{C}, 5 \% \mathrm{CO}_{2}\right)$, as described above, were washed out and stimulated for $2 \mathrm{~h}\left(37^{\circ} \mathrm{C}, 5 \% \mathrm{CO}_{2}\right)$ with $\mathrm{nGE}$ or $\mathrm{dGE}(5 \mu \mathrm{g} / \mathrm{ml})$, or supplemented with 100 $\mu \mathrm{l}$ of cRPMI (control). Then, macrophages were washed out and the autologous, spleen T lymphocytes $(100 \mu \mathrm{l} /$ well) were added to the cells at the concentration of $2.5 \times 10^{6}$ cells $/ \mathrm{ml}$ of viable cells. The wells were supplemented with $100 \mu \mathrm{l}$ cRPMI or PHA $(2 \mu \mathrm{g} / \mathrm{ml})$ and incubated for further $72 \mathrm{~h}$. At $18 \mathrm{~h}$ before the end of culture, $1 \mu \mathrm{Ci}$ of $\left[{ }^{3} \mathrm{H}\right]$-thymidine was added to each well to estimate cell proliferation. All cell cultures were settled in triplicate.

Cell proliferation. The incorporation of thymidine was measured using a microbeta scintillation counter after harvesting the cells on fibre filters. All cultures were settled in 3 repeats. The results were expressed as mean $\mathrm{cpm} /$ culture \pm standard deviation (S.D.). The stimulation index (SI), expressing the relative $\mathrm{cpm}$ ratio, was calculated by dividing the $\mathrm{cpm}$ counts/min obtained for the cell cultures with a stimulant by the cpm counts/min for the cell cultures without a stimulant. The SI values greater than or equal to 1.5 were considered as a positive result in the proliferation assay.
Phenotyping of proliferating lymphocytes. To assess the distribution of proliferating immune cell subsets, cytospin preparations of the cells from cell cultures in vitro were made. The cells attached to the slides were incubated for $30 \mathrm{~min}$ with mouse monoclonal primary guinea pig-specific antibodies: anti-CD3 (IgG1, clone CT5), anti-CD4 (IgG1, clone CT7), anti-CD8 (IgG1, clone CT6) and anti-B (IgG1, clone MsGp10) (AbD Serotec, Oxford, UK). To detect the binding of primary mouse antibodies, Alkaline Phosphatase - Anti-Alkaline Phosphatase (APAAP), Dako RealTM Detection System, was used as recommended by the manufacturer (DAKO, Glostrup, Denmark). The percentage of the cells with a specific phenotype was evaluated by four independent experiments, using a light microscope.

mRNA levels for cytokine evaluation. tMLNL $\left(5 \times 10^{6}\right.$ cells $\left./ \mathrm{ml}\right)$ whole leukocyte populations, distributed to 96 -well microplates $(100 \mu \mathrm{l} /$ well), were stimulated for $72 \mathrm{~h}\left(37^{\circ} \mathrm{C}, 5 \% \mathrm{CO}_{2}\right)$ with $5 \mu \mathrm{g} / \mathrm{ml} \mathrm{H}$. pylori $\mathrm{GE}, 2 \mu \mathrm{g} / \mathrm{ml}$ PHA, or left unstimulated in cRPMI. The Reverse Transcription Polymerase Chain Reaction (RT-PCR) was used to detect mRNA in adherent cells, encoding IL-1 $\beta$ and IL-8, and TGF- $\beta$ as well as IFN- $\gamma$ in nonadherent leukocytes. Total RNA was extracted from adherent and nonadherent leukocytes using SV Total RNA Isolation System (Promega Corporation, Madison, USA) following the manufacturer'protocol. The RNA samples were purified with Amplification Grade I Deoxyribonuclease (Sigma, St. Louis, USA) and stored at $-80^{\circ} \mathrm{C}$ in sterile, nuclease free water. Purified total RNAs $(0.005 \mu \mathrm{g} / \mathrm{ml})$ were reverse-transcribed into cDNA according to the manual of the Enhanced Avian HS RT-PCR kit (Sigma, St. Louis, USA). The reaction was carried out in the presence of enhanced avian reverse transcriptase, at $42^{\circ} \mathrm{C}$ for 50 min. PCR was performed using the mixture of equivalent amounts of cDNA of each sample $(5 \mu \mathrm{l})$, sets of primers for guinea pig IL-1 $\beta$, IL-8, TGF- $\beta$ and IFN- $\gamma$ (Table 1). $\beta$-actin was used as a positive and internal control for RT-PCR. Reverse transcriptasenegative controls were used to ensure that PCR amplification of cDNA was not a result of contamination with genomic DNA. Amplified products were electrophoresed on ethidium bromide-stained gels and visualized by UV illumination.

Statistical analysis. The Statistica 10 PL software with non-parametric tests was used: the Mann-Whitney $\mathrm{U}$ test (for unpaired data) to verify the hypothesis that two compared samples came from two statistically different populations.

Table 1. The sets of primers and polymerase chain reaction (PCR) conditions used for evaluation of cytokine mRNA levels, including products length.

\begin{tabular}{|c|c|c|c|}
\hline Target & $\begin{array}{l}\text { Sequences }\left(5^{\prime}-3^{\prime}\right) \\
\text { (F: forward, R: reverse) }\end{array}$ & Annealing temperature \& number of PCR cycles & Product length \\
\hline$\beta$-actin & $\begin{array}{l}\text { F, } 5 \text { 'CCAACTGGGACGACATGGAG 3' } \\
\text { R, } 5 \text { 'CATACCCCTCGTAGATGGGC 3' }\end{array}$ & $\begin{array}{l}55^{\circ} \mathrm{C} \\
35\end{array}$ & $279 \mathrm{bp}$ \\
\hline IL-1 $\beta$ & $\begin{array}{l}\text { F, 5' GCCCAGGCAACAGCTCTC 3' } \\
\text { R, 5' GGAGTCTCTACCAGCTCAACTTGG 3' }\end{array}$ & $\begin{array}{l}57^{\circ} \mathrm{C} \\
35\end{array}$ & $74 \mathrm{bp}$ \\
\hline IL-8 & $\begin{array}{l}\text { F, 5' GGCAGCCTCCCTGCTCTCT 3' } \\
\text { R, 5' CAGCTCCGAGACCAACTITGT 3' }\end{array}$ & $\begin{array}{l}55^{\circ} \mathrm{C} \\
35\end{array}$ & $67 \mathrm{bp}$ \\
\hline TGF- $\beta$ & $\begin{array}{l}\text { F, 5'CATCGATATGGAGCTGGTGAAG 3' } \\
\text { R, 5' GCCGTAATITGGACAGGATCTG 3' }\end{array}$ & $\begin{array}{l}54^{\circ} \mathrm{C} \\
35\end{array}$ & $71 \mathrm{bp}$ \\
\hline IFN- $\gamma$ & $\begin{array}{l}\text { F, 5' ATTTCGGTCAATGACGAGCAT 3' } \\
\text { R, 5' GTTCCTCTGGTCGGTGACA 3' }\end{array}$ & $\begin{array}{l}54^{\circ} \mathrm{C} \\
35\end{array}$ & $88 \mathrm{bp}$ \\
\hline
\end{tabular}




\section{Guinea pigs inoculated with $0.85 \% \mathrm{NaCl}$ (control group)}
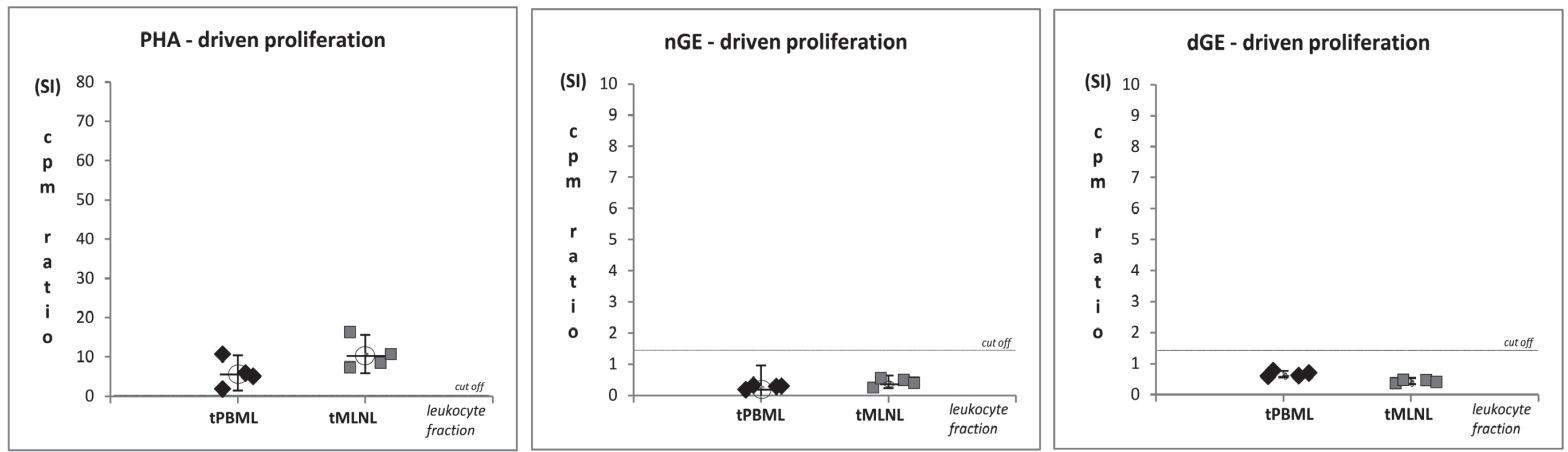

Guinea pigs inoculated with $\mathrm{H}$. pylori
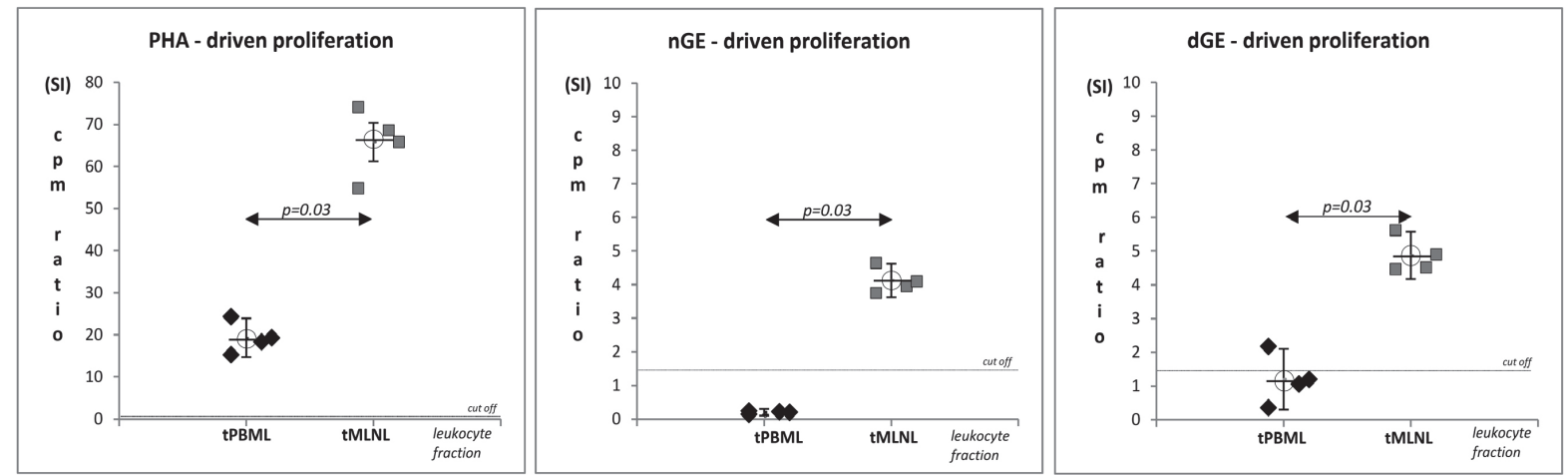

Figure 3. H. pylori antigen-driven proliferative response of lymphocytes in single-stage cultures of total mesenteric lymph node leukocytes (tMLNL) and total peripheral blood mononuclear leukocytes (tPBML).

Non-separated MLNL and PBML were incubated for $72 \mathrm{~h}$ in the presence of $H$. pylori antigens, present in the glycine acid extract (GE), or phytohaemagglutinin (PHA). The proliferating activity of lymphocytes was evaluated on the basis of $\left[{ }^{3} \mathrm{H}\right]$-thymidine incorporation. The stimulating index (SI) was calculated by dividing the radioactivity counts (cpm) for the cell cultures in the presence of a stimulus by the counts for control cell cultures in RPMI-1640 alone. Shown are SI \pm S.D.

\section{RESULTS}

The level of $H$. pylori-driven proliferative response of lymphocytes in single-stage cultures of tMLNL and tPBML

Data in Fig. 3 show that lymphocytes present in total fractions of MLNL and PBML, isolated from $H$. pylori uninfected and $H$. pylori infected guinea pigs, responded effectively with proliferation in the milieu of PHA. The lymphocytes from animals infected with $H$. pylori responded to PHA to a higher level than the cells of control animals. In contrast to PHA, H. pylori GE, native or denatured, did not stimulate blastogenic response of lymphocytes present in the tPBML fraction of both control and $H$. pylori infected animals. By comparison, the lymphocytes present in the tMLNL fraction of $H$. pylori infected, but not control animals, proliferated successfully in response to native as well as denatured $H$. pylori GE. The response to dGE was stronger than to $\mathrm{nGE}$. The denatured form of $H$. pylori GE had no significant influence on PHA-driven proliferative response of lymphocytes present in the tMLNL fraction of control and H. pylori infected animals (Fig. 4). In the milieu of dGE, where the lymphocytes proliferated intensively, the percentage of $\mathrm{T}$ lymphocytes was about 22 times higher than the percentage of $\mathrm{B}$ lymphocytes. Moreover, $\mathrm{CD}^{+}$
T lymphocytes exceeded 19 times the percentage of $\mathrm{CD}^{+}$lymphocytes.

\section{Cytokine milieu in relation to $H$. pylori-driven proliferation of lymphocytes in single-stage cultures of tMNLN}

Since cytokines produced by accessory cells and lymphocytes might affect lymphocyte proliferation in the cultures containing non-separated leukocytes of mesenteric lymph nodes, after $72 \mathrm{~h}$ stimulation of the cells in the presence or absence of PHA, nGE or dGE, we estimated mRNA levels of monocyte derived cytokines (IL- 8 and IL-1 $\beta$ ) as well as lymphocyte derived cytokines (IFN- $\gamma$ and TGF- $\beta$ ).

Data in Fig. 5 show the presence of IL-8 mRNA (67 bp product) in the cultures of monocytes, non-stimulated or preincubated in vitro with PHA, H. pylori nGE as well as dGE, which were present in mesenteric lymph nodes of control and $H$. pylori infected animal. The mRNA for IL-1 $\beta$ (74 bp product) was detected in monocytes isolated from guinea pigs uninfected with $H$. pylori, in the cell cultures supplemented with $H$. pylori GEs as well as with PHA, but not in the milieu of RPMI-1640 alone. In contrast, mesenteric lymph node monocytes of $H$. pylori infected guinea pigs did not express mRNA for IL-1 $\beta$ in any combination of cell cultures. The mRNA for lymphocyte-derived cytokines such as IFN- $\gamma$ (88 bp prod- 


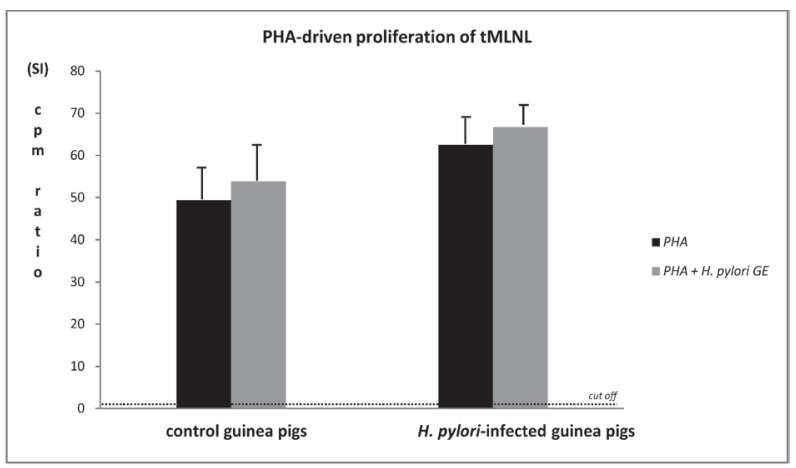

Figure 4. PHA-driven proliferation of lymphocytes present in the total mesenteric lymph node leukocyte fraction (tMLNL) in the milieu of $H$. pylori antigens.

The modulation of phytohaemagglutinin (PHA)-driven proliferation of lymphocytes by $H$. pylori antigens present in the glycine acid extract, denaturated by heating (dGE), was investigated in the cell cultures of non-separated leukocytes from mesenteric lymph nodes, which were cultivated for $72 \mathrm{~h}$ in RPMI-1640 alone, with PHA, or with PHA and dGE. Proliferating activity of lymphocytes was evaluated on the basis of $\left[{ }^{3} \mathrm{H}\right]$-thymidine incorporation. The results are presented as stimulating index (SI) calculated by dividing the radioactivity counts (cpm) for the cell cultures in the presence of PHA and dGE or for the cell cultures in PHA alone, by the counts for control cell cultures in RPMI-1640 alone. The results are expressed as SI \pm S.D. The differences between PHA and PHA + $H$. pylori GE-driven proliferation of lymphocytes from control and H. pylori-infected animals were not statistically significant $(p>0.05)$.

uct) and TGF- $\beta$ (71 bp product) was also investigated. The mRNA for TGF- $\beta$ was detected in non-adherent lymphocytes, from mesenteric lymph nodes of $H$. pylori uninfected as well as $H$. pylori infected guinea pigs, propagated in vitro in the presence of PHA, H. pylori GEs or in the milieu of RPMI-1640 alone. The mRNA for
IFN- $\gamma$ was detected in the lymphocytes of $H$. pylori unifected guinea pigs, incubated in the RPMI-1640 alone or in such medium containing PHA or H. pylori GEs. By comparison, the mRNA for IFN- $\gamma$ was detected in the lymphocytes from $H$. pylori infected guinea pigs stimulated with PHA and $H$. pylori GEs but not in the milieu of RPMI-1640 alone.

The level of $H$. pylori-driven proliferative response of spleen lymphocytes in two-stage cultures with immature and mature bone marrow macrophages

The lack of $\left[{ }^{3} \mathrm{H}\right]$-thymidine incorporation into $H$. pylori GE treated tPBML shown by us in this study (Fig. 3), might suggest an inability of peripheral blood lymphocytes to respond to $H$. pylori antigens by proliferation, or the lack of $H$. pylori specific lymphocytes among circulating tPBML. This prompted us to examine whether $H$. pylori specific $\mathrm{T}$ lymphocytes are localized in the spleen, which in addition to the lymph nodes is an important peripheral lymphoid organ where development of adaptive immune responses takes place. This processes must be preceded by macrophage-lymphocyte interactions, necessary for successful antigen presentation. The effectiveness of processing and presentation of antigens by macrophages depends on their activity and maturation. To evaluate the role of macrophages as antigen presenting cells in this study we developed a two-step culture model for the estimation of the proliferative activity of spleen $\mathrm{T}$ lymphocytes utilizing monolayers of immature and mature bone marrow-derived macrophages non-pulsed, or pulsed with denaturated H. pylori GE antigens, and PHA. The results presented in Fig. 6 show that the splenocytes of both groups of animals proliferated in two-stage cultures with immature and mature macrophages in response to PHA, confirm-

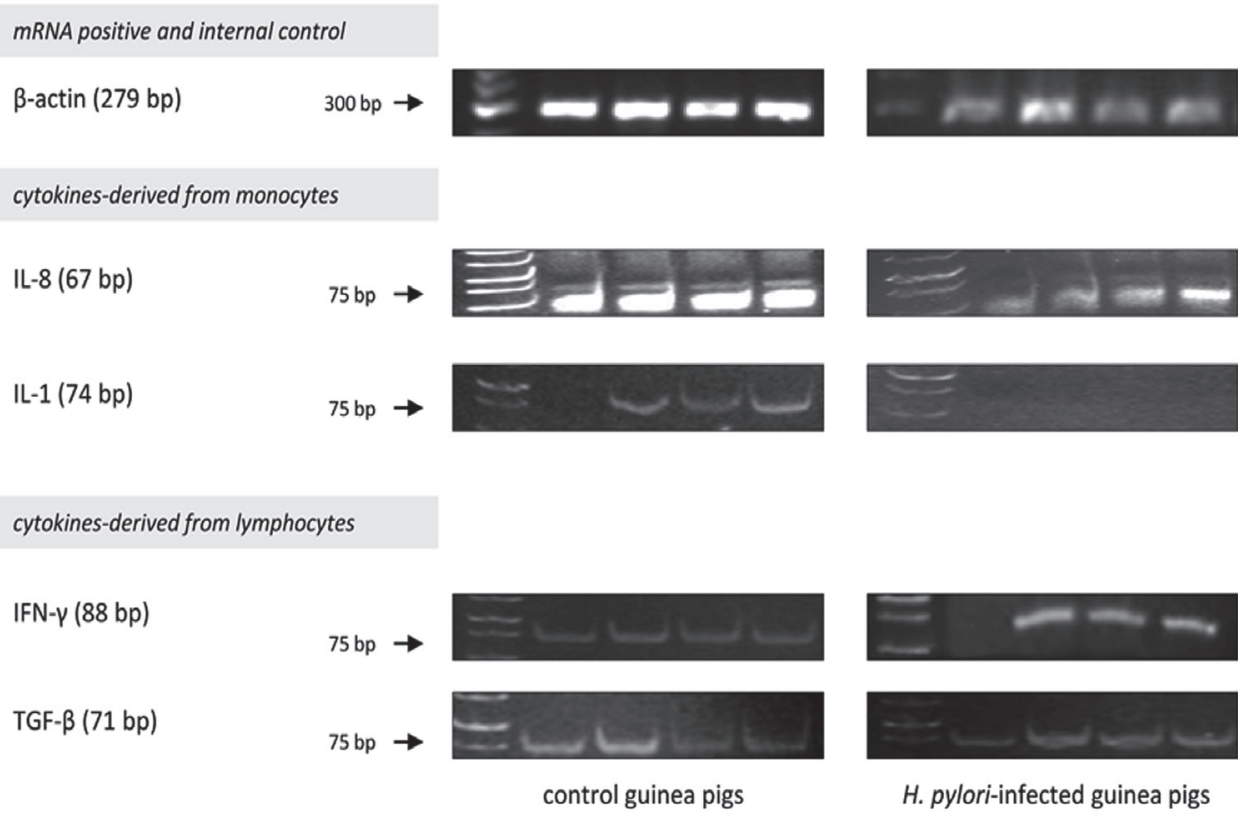

Figure 5. The mRNA levels for selected cytokines.

Total fraction of mesenteric lymph node leukocytes (tMLNL) from guinea pigs, uninfected or infected with $H$. pylori, were stimulated for $72 \mathrm{~h}$ with $\mathrm{H}$. pylori glycine acid extract, native (nGE) or denaturated by heating (dGE), phytohaemagglutinin (PHA) or left unstimulated (RPMI-1640 alone). Reverse Transcription Polymerase Chain Reaction (RT-PCR) was used to detect mRNA encoding cytokines derived from monocytes, such as interleukin 1 beta (IL-1 $\beta$ ) and IL-8 as well as cytokines derived from lymphocytes, including transforming growth factor beta (TGF- $\beta$ ) and interferon gamma (IFN- $\gamma$ ). $\beta$-actin mRNA level consisted of positive control. $\mathrm{M}$ - molecular standard, bp - base pairs. 


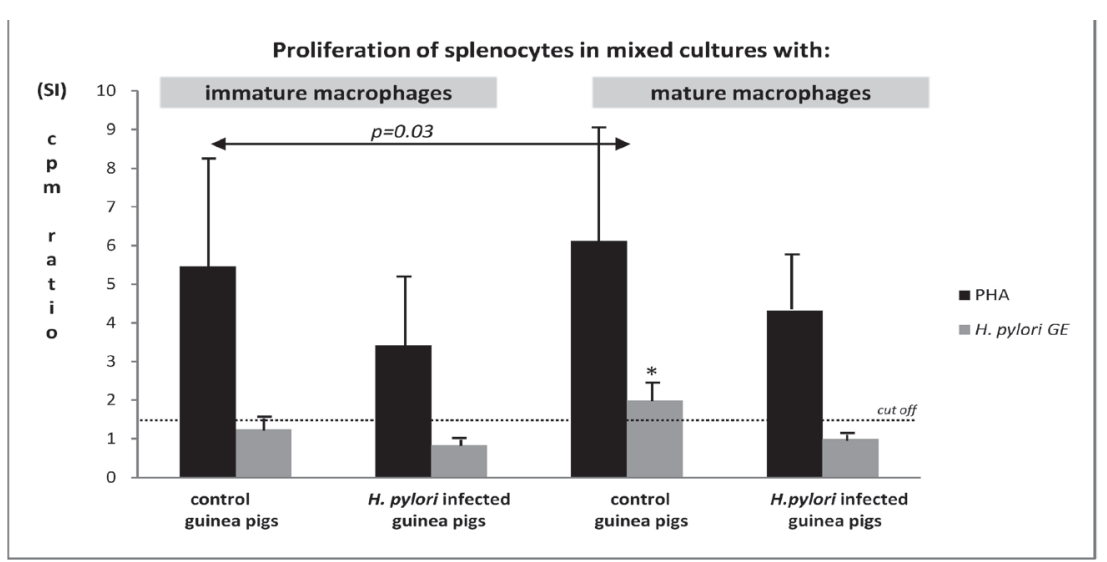

Figure 6. The level of H. pylori-driven proliferative response of spleen lymphocytes in twostage cultures with immature and mature bone marrow macrophages.

Two-stage cultures containing immature or mature (resting for 5 days in RPMI-1640 medium) bone marrow macrophages and autologous $T$ lymphocytes from the spleen of guinea pigs uninfected or infected with $H$. pylori were prepared. The lymphocytes were added to non treated macrophages, or to macrophages pulsed for $2 \mathrm{~h}$ with $H$. pylori glycine acid antigens: dGE or nGE. After washing, the macrophages were co-incubated with autologous spleen T lymphocytes, in the proportion 1:5. The cell cultures were supplemented with culture medium or phytohaemagglutinin - PHA, and incubated for further $72 \mathrm{~h}$. The proliferating activity of lymphocytes was evaluated on the basis of $\left[{ }^{3} \mathrm{H}\right]$-thymidine incorporation. Columns show main mean values \pm S.D. The stimulating index (SI) was calculated by dividing the radioactivity counts (cpm) for the cell cultures containing pulsed macrophages by the radioactivity counts for the cultures containing non-pulsed macrophages.

ing the proliferative properties of the cells, although lymphocytes of $H$. pylori infected animals proliferated to a lower extent. $\mathrm{T}$ cell enriched splenocytes from $H$. pylori uninfected guinea pigs slightly responded by proliferation to $H$. pylori dGE antigens $(\mathrm{SI}=1.8)$, presented by mature macrophages, pulsed with these antigens. However, the spleen lymphocytes of $H$. pylori infected animals did not proliferate in the presence of macrophages pulsed with H. pylori dGE, either immature or mature.

\section{DISCUSSION}

The lymphocyte proliferating activity is an important indicator of their propagation during the development of adaptive immune responses against microbial pathogens. This activity also allows following the distribution of antigen-specific lymphocytes during the course of infection. On the other hand, excessive proliferation of the cells responding to $H$. pylori compounds may suggest their mutagenic properties. Changes occurring in the gastric epithelium, colonized by $H$. pylori lead to the penetration of $H$. pylori antigens across the gastric mucosa, where in the lamina propria they can be processed by macrophages via pathogen recognition receptors (PRR), resulting in the activation of $\mathrm{T}$ lymphocytes and development of both local and systemic inflammatory responses (Dubreuil et al., 2002; Wessler \& Backert, 2008).

The $\mathrm{T}$ cell proliferation and cytokine production by peripheral blood lymphocytes were considered as markers of the inflammatory responses to $H$. pylori infection in the milieu of gastric mucosa (Fan et al., 1995; Chmiela et al., 1996). However, it was shown that $\mathrm{T}$ cell responses in peripheral blood do not reflect the local processes in the gastric mucosa (Karttunen et al., 1991). In the subjects with chronic $H$. pylori related gastritis, the dominant $\mathrm{T}$ cell response to $H$. pylori, both at the level of gastric mucosa and in circulation, was a Th1 response (Ren et al., 2000).
In order to examine whether there is a link between $\mathrm{T}$ cell responsiveness and $H$. pylori infection, in this study we performed experiments using a guinea pig model of $H$. pylori infection, which allowed the identification of $H$. pylori specific activation of $\mathrm{T}$ cells. We investigated $\mathrm{T}$ cell proliferation and cytokine mRNA levels in the cell cultures of mesenteric lymph node lymphocytes or peripheral blood lymphocytes, isolated from $H$. pylori infected and $H$. pylori non-infected guinea pigs, in the milieu of $H$. pylori antigens, PHA or culture medium alone. The cell proliferation was also assessed in the cultures of splenocytes, which were co-cultured with immature or mature macrophages, pulsed with $H$. pylori antigens. We showed that in the mesenteric lymph nodes of guinea pigs after 4 weeks postinfection, but not in healthy animals, there were $H$. pylori specific $\mathrm{T}$ lymphocytes responding in vitro to $H$. pylori $\mathrm{GE}$ antigens by proliferation. These responses were more effective to heat inactivated than native GE, which could be due to better processing and presentation of denaturated protein antigens of $H$. pylori GE. It could mimic the fate of $H$. pylori antigens in acidic environment of the stomach.

The blastogenic activity of $\mathrm{T}$ lymphocytes in the tMLNL fraction was shaped by their interaction with antigen presenting cells, which were present in the cell cultures during the whole experiment. Moreover, the balance between cytokines derived from adherent leukocytes, including IL- 8 as well as IFN- $\gamma$ and regulatory TGF- $\beta$, delivered by lymphocytes, was probably important for the successful proliferation of lymphocytes. In contrast, mRNA for IL-1 $\beta$ was not detected in the tMLNL isolated from $H$. pylori infected animals, in the cell cultures containing GE antigens and probably this cytokine was not crucial for the expansion of lymphocytes. Since mRNA for IL-1 $\beta$ was detected in the tMLNL from H. pylori uninfected guinea pig, in the cultures in the milieu of $H$. pylori GEs, it is possible that $H$. pylori infection could modulate the IL- $1 \beta$ responsiveness of the cells, or their distribution. The time of exposition to $H$. pylori antigens in vivo could also play a role. High levels of mucosal IL-1 $\beta$ mRNA were also observed early in the $H$. $p y$ lori infection in Mongolian gerbils, reaching maximum at 4 weeks and then rapidly declining (Yamaoka et al., 2005). In the gastric mucosa of $H$. pylori infected humans IL-1 $\beta$ is also secreted. This cytokine is a powerful inhibitor of gastric acid secretion that plays an important role in initiating and amplifying the inflammatory response to H. pylori infection (Noach et al., 1994).

In humans infected with $H$. pylori, chronic active gastritis is associated with an increased CD4/CD8 cell ratio within the gastric mucosa due to the accumulation of $\mathrm{CD}^{+} \mathrm{T}$ lymphocytes in the lamina propria (Portal-Celhey et al., 2006). H. pylori infection results in a Th1 predominant host immune response in the gastric mucosa, characterized by the induction of IFN- $\gamma$ genes and elevated levels of TNF- $\alpha$ (Tumuala et al., 2004). In our 
study, in the cell cultures of tMLNL, in the milieu of GE, where the lymphocytes of $H$. pylori infected guinea pigs proliferated intensively, the percentage of $T$ lymphocytes was about 22 times higher than the percentage of $\mathrm{B}$ lymphocytes. Moreover, CD4 ${ }^{+} \mathrm{T}$ lymphocytes exceeded 19 times the percentage of $\mathrm{CD}^{+}$lymphocytes. These results showed the domination of effector $\mathrm{CD}^{+} \mathrm{T}$ lymphocytes in $H$. pylori infected guinea pigs, four weeks postinfection. Recently, it has been presented (Kronsteiner et al., 2013) that H. pylori infection in a guinea pig model induced a predominant systemic Th1 response in vivo characterized by increased percentages of $\mathrm{CD}^{+}{ }^{+} \mathrm{T}$ lymphocytes expressing the Th1-associated transcription factor Tbet and elevated IFN- $\gamma$ mRNA in PBML. A transient single peak was observed at day 7 postinfection followed by a sustained increase in $\mathrm{CD}^{+}$ Tbet $^{+}$cells from day 28 to day 49 postinfection in $H$. pylori infected animals. At day 28 postinfection there was a coincidence between the increase of $\mathrm{CD}^{+}{ }^{+} \mathrm{Tbet}^{+}$lymphocytes and increased transcripts of IFN- $\gamma$ mRNA in PBML cultures. A sharp increase in $\mathrm{CD} 8 \beta^{+}$Tbet $^{+}$cells in $H$. pylori infected guinea pigs was also detected. This model showed that it is possible to measure the cellular response rates, based on the activity of peripheral blood leukocytes, but not earlier than 28 days after the $H$. pylori challenge. This is consistent with our results, indicating the lack of proliferative response of $\mathrm{T}$ lymphocytes specific for $H$. pylori antigens in the circulation, as well as in the spleen of $H$. pylori infected guinea pigs after 30 days postinfection. However, the differences in the appearance of immune effector cells can also be a result of a various antigenic composition of $H$. pylori strains used for inducing the infection and different susceptibility of animals. On the other hand, it is also necessary to consider the immunomodulatory properties of $H$. pylori compounds, for instance CagA antigen, VacA toxin, LPS, low molecular weight secretory protein and arginase can diminish the proliferative activity of immunocompetent cells (Paziak-Domańska et al., 2000; Mahdavi et al., 2002; Gebert et al., 2003; Sundrud et al., 2004; Zabaleta et al., 2004; Gerhard et al., 2005; Torres et al., 2007; Grębowska et al., 2008). It has been suggested that $H$. pylori has evolved a number of features to evade detection by the human immune system. Many of them involve glyco-conjugates including the LPS, the peptidoglycan layer, glycoproteins, and glycosylated cholesterol (Rubin \& Trent, 2013). In contrast to immunocompetent cells, some $H$. pylori compounds may induce hiperproliferation of gastric epithelial cells including CagA protein ( $\mathrm{MunOz}$ et al., 2007). It was also shown that the immune/inflammatory response to $H$. pylori indirectly, can influence the rate of epithelial cells proliferation (Fan et al., 1996).

In this study H. pylori GE antigens did not stimulate the propagation of lymphocytes in tPBML fraction or blastogenic response of splenocytes, isolated from H. pylori infected guinea pigs, co-cultured with monocytes pulsed with H. pylori GE antigens. However, the general proliferative properties of lymphocytes were not affected, which was shown by the lack of inhibition of PHA-driven proliferative responses of lymphocytes isolated from both $H$. pylori infected and uninfected guinea pigs, in the presence or absence of $H$. pylori antigens. Searching for the reason of diminished proliferative response of splenocytes, we thought that the maturity of monocyte-derived macrophages could be essential for the expression of their properties for antigen presentation. Therefore, in this study we used a two-stage cell culture system with immature and mature bone marrow-derived monocytes, pulsed with $H$. pylori GE anti- gens, which were then mixed with spleen-derived lymphocytes. The proliferative responses of splenocytes from $H$. pylori infected animals were not triggered in the presence of $H$. pylori GE pulsed monocytes, both immature and mature. This might indicate the lack of antigen specific response. However, the blockage of antigen presenting function of bone marrow-derived monocytes by $H$. pylori antigens cannot be excluded. Although macrophages can initiate immune responses, they are also capable of suppressing T-cell responses. Macrophages exposed to activating agents such as mitogens, IFN- $\gamma$ and LPS can inhibit both mitogen- and antigen-specific T-cell proliferation. This inhibition can be mediated by soluble substances such as prostaglandin $\mathrm{E}_{2}$, direct cell contact with $\mathrm{T}$ cells, or by the induction of suppressing cytotoxic T cells (Kirschmann et al., 1994; McKernan et al., 1988). It was shown that $H$. pylori LPS expressed a very weak, if any, capacity to stimulate the proliferation of tPBML from dyspeptic patients (Rudnicka et al., 2003). In the group of LPS responders the mature macrophages pulsed with $H$. pylori LPS were found to be a weak stimulus for autologous non-adherent lymphocytes (Grębowska et al., 2010). It was also suggested that $H$. pylori-mediated disruption of phagosome maturation may affect the nature of the inflammatory immune response in the gastric mucosa and promote the long-persitence of $H$. pylori infection (Borlace et al., 2012). Moreover, $H$. pylori-infected macrophages may induce the differentiation of Th17 cells, which represent a novel subset of $\mathrm{CD}^{+}$lymphocytes associated with chronic inflammation (Zhuang et al., 2011).

It is also necessary to comment on slightly enhanced proliferating activity of splenocytes isolated from $H$. $p y$ lori uninfected guinea pigs co-cultured with mature macrophages pulsed with $H$. pylori GE. This proliferative response was probably induced by crossreacting antigens. Previously, it was shown that several bacterial species for instance Pseudomononas aeruginosa, Campylobacter jejuni and Haemophilus influenzae may cause false-positive titres of antibody to $H$. pylori (Johansen et al., 1995). Similarly, mRNA levels of cytokines in $H$. pylori uninfected guinea pigs might reflect a cellular response to bacterial compounds other than $H$. pylori antigens.

In order to explain the differences in reactivity to $H$. pylori antigens of $\mathrm{T}$ cells from peripheral blood and those examined in situ, or isolated from gastric mucosa, the attention should be focused on the urease produced by $H$. pylori. Locally in the stomach, $\mathrm{T}$ and $\mathrm{B}$ lymphocytes are activated by urease, whereas peripheral blood lymphocytes are beyond the urease influence. The urease may affect cell activation by modifying the levels of cytokines and the activity of recruited inflammatory cells (Kohda et al., 1999).

The lack of proliferative response to $H$. pylori GE antigens of peripheral blood and spleen lymphocytes in $H$. pylori infected guinea pigs might be also discussed in the context of homing molecules. In humans, $\mathrm{CD}^{+}{ }^{+} \mathrm{T}$ lymphocytes with high expression of the a4 $\beta 7$ homing receptor or L-selectin responded to $H$. pylori antigens by proliferation better than $\mathrm{T}$ lymphocytes lacking of such receptors. This means that T cells responding to $H$. pylori antigens, expressing such molecules, might be localized in an organized lymphoid tissue in jejunum, or in the gastric mucosa, but not in the circulation. It is possible that $\mathrm{T}$ lymphocytes stimulated by $H$. pylori antigens in the stomach, or jejunum, might differentiate into effector cells in Peyer's patches, and then migrate along circulation to the gastric mucosa via endothelial MAdCAM-1 (mucosal adressin cellular adhesion molecule 1), which is 
the ligand for a4 $\beta 7$. Therefore, this is the reason why the reactivity of the gastric tissue and circulating lymphocytes could differ (Quiding-Jarbrink et al., 2001).

\section{CONCLUSION}

This study showed that a guinea pig model is suitable for investigating the course of $H$. pylori-triggered immune responses in regard to the expansion of antigen specific $\mathrm{T}$ lymphocytes, the effectiveness of macrophages as antigen presenting cells and the secretion of cytokines. However, further studies are needed to explain the kinetics and molecular nature of the immune processes related to $H$. pylori infection in guinea pigs, and to make comparisons with the mechanisms associated with $H$. pylori infections in humans.

\section{Acknowledgements}

This study was supported by the National Science Centre grant PRELUDIUM 5 (UMO-2013/09/N/ NZ6/00805), the Ministry of Science and Higher Education grant (NN 303451738) and the Project entitled "PhD Students, Regional Investment in Young Scientists. D-RIM BIO acronym" co-financing from the European Union under the Operational Programme $\mathrm{Hu}-$ man Capital Investment, sub-measure 8.2.1.

\section{REFERENCES}

Algood HMS, Cover T (2006) Helicobacter pylori persistence: an overview of interactions between $H$. pylori and host immune defences. Clin Microbiol Rev 19: 597-613.

Borlace GN, Keep SJ, Prodoehl MIR, Jones HF, Butler RN, Brooks DA (2012) A role for altered phagosome maturation in the longterm persistence of Helicobacter pylori infection. Am J Physiol Gastrointest Liver Physiol 303: G169-G179.

Chmiela M, Paziak-Domańska B, Ljungh A, Wadström T, Rudnicka W (1996) The proliferation of human $\mathrm{T}$ lymphocytes stimulated by Helicobacter pylori antigens. Immunobiology 195: 199-208.

Dubreuil JD, Giudice GD, Rappuoli R (2002) Helicobacter pylori interactions with host serum and extracellular matrix proteins: potential role in the infectious process. Microbiol Mol Biol Rev 66: 617-629.

Fan XG, Kelleher D, Fan XJ, Xia HX, Keeling PWN (1996) Helicobacter pylori increases proliferation of gastric epithelial cells. Gut 38: 19-22.

Fan XG, Yakoob J, Fan XJ, Keeling PWN (1995) A change of IL-1 and IL-4 production in patients with Helicobacter pylori infection. $\mathrm{Me}$ diators Inflamm 4: 289-292.

Gebert B, Fischer W, Weiss E, Hoffmann R, Haas R (2003) Helicobacter pylori vacuolating cytotoxin inhibits $\mathrm{T}$ lymphocyte activation. Science 301: 1099-1102

Gerhard M, Schmees C, Voland P, Endres N, Sander M, Reindl W, Rad R, Oelsner M, Decker T, Mempel M, Hengst L, Prinz C (2005) A secreted low-molecular-weight protein from Helicobacter pylori induces cell-cycle arrest of T cells. Gastroenterology, 128: 1327-1339.

Grębowska A, Moran AP, Matusiak A, Bąk-Romaniszyn L, Czkwianianc E, Rechciński T, Walencka M, Płaneta-Małecka I, Rudnicka W, Chmiela M (2010) Helicobacter pylori lipopolysaccharide activity in human peripheral blood mononuclear leukocyte cultures. J Physiol Pharmacol 61: 437-442.

Johansen HK, Norgard A, Andersen L, Jensen P, Nielsen H, Hoiby N (1995) Cross-reactive antigens shared by Pseudomonas aeruginosa, Helicobacter pylori, Campylobacter jejuni, and Haemophilus influenzae may cause false-positive titres of antibody to H. pylori. Clin Diagn Lab Immunol 2: 149-155.

Karttunen R, Andersson G, Poikonen P, Kosunen TU, Karttunen T, Juutinen K, Niemelä S (1990) Helicobacter pylori induces lymphocyte activation in peripheral blood cultures. Clin Exp Immunol 82: 485488 .
Kirschmann DA, He X, Murasko DM (1994) Inhibition of macrophage-induced, antigen-specific T-cell proliferation by poly I:C role of suppressor macrophages. Immunology 82: 238-243.

Kohda K, Tanaka K, Aiba Y, Yasuda M, Miwa T, Koga Y (1999) Role of apoptosis induced by Helicobacter pylori infection in the development of duodenal ulcer. Gut 44: 456-462.

Kronsteiner B, Bassaganya-Riera J, Philipson C, Viladomiu M, Carbo A, Pedragosa M, Vento S, Hontecillas R (2013) Helicobacter pylori infection in a guinea pig model is dominated by Th1 and cytotoxic $\mathrm{CD}^{+} \mathrm{T}$ cell responses. Infect Immun 81: 3803-3813.

Mahdavi J, Sondén B, Hurtig M, Olfat FO, Forsberg L, Roche N, Angstrom J, Larsson T, Teneberg S, Karlsson KA, Altraja S, Wadström T, Kersulyte D, Berg DE, Dubois A, Petersson C, Magnusson KE, Norberg T, Lindh F, Lundskog BB, Arnqvist A, Hammarström L, Borén T (2002) Helicobacter pylori SabA adhesin in persistent infection and chronic inflammation. Science 297: 573-578.

McKernan LN, Blank KJ, Spitalny GL, Murasko DM (1988) Inhibition of macrophage-induced antigen-specific $\mathrm{T}$ cell proliferation by gamma interferon. Cell Immunol 114: 432-437.

Muñoz L, Camorlinga M, Hernández R, Giono R, Ramón G, Muñoz $\mathrm{O}$, Torres J (2007) Immune and proliferative cellular responses to Helicobacter pylori infection in the gastric mucosa of Mexican children. Helicobacter 12: 224-230.

Noach LA, Bosma NB, Jansen J, Hoek FJ, van Deventer SJ, Tytgat GN (1994) Mucosal tumor necrosis factor-alpha, interleukin-1 beta, and interleukin-8 production in patients with Helicobacter pylori infection. Scand J Gastroenterol 29: 425-429.

Paziak-Domańska B, Chmiela M, Jarosińska A, Rudnicka W (2000) Potential role of $\mathrm{CagA}$ in the inhibition of $\mathrm{T}$ cell reactivity in Helicobacter pylori infections. Cell Immunol 202: 136-139.

Portal-Celhay C, Perez-Perez GI (2006) Immune responses to Helicobacter pylori colonization: mechanisms and clinical outcomes. Clin Sci (Lond) 110: 305-314.

Quiding-Jarbrink M, Ahlstedt I, Lindholm C, Johansson E, Lonroth H (2001) Homing commitment of lymphocytes activated in the human gastric and intestinal mucosa. Gut 49: 519-525.

Rechciński T, Chmiela M, Małecka-Panas E, Płaneta-Małecka I, Rudnicka W (1997) Serological indicators of Helicobacter pylori infection in adult dyspeptic patients and healthy blood donors. Microbiol Immunol 41: 387-393.

Ren Z, Pang G, Lee R, Batey R, Dunkley M, Borody T, Clancy R (2000) Circulating T-cell response to Helicobacter pylori infection in chronic gastritis. Helicobacter 5: 135-141.

Rubin EJ, Trent MS (2013) Colonize, evade, flourish: How glyco-conjugates promote virulence of Helicobacter pylori. Gut Microbes 4: 1-15.

Rudnicka W, Jarosińska A, Bak-Romaniszyn L, Moran AP, PłanetaMałecka I, Wadström T, Chmiela M (2003) Helicobacter pylori lipopolysaccharide in the IL-2 milieu activates lymphocytes from dyspeptic children. FEMS Immunol Med Microbiol 36: 141-145.

Sundrud MS, Torres VJ, Unutmaz D, Cover TL (2004) Inhibition of primary human $\mathrm{T}$ cell proliferation by Helicobacter pylori vacuolating toxin $(\mathrm{VacA})$ is independent of VacA effects on IL-2 secretion. Proc Natl Acad Sci USA 101: 7727-7732.

Torres VJ, VanCompernolle SE, Sundrud MS, Unutmaz D, Cover TL (2007) Helicobacter pylori vacuolating cytotoxin inhibits activation-induced proliferation of human $\mathrm{T}$ and $\mathrm{B}$ lymphocyte subsets. J Immunol 179: 5433-5440.

Tummala S, Keates S, Kelly CP (2004) Update on the immunologic basis of Helicobacter pylori gastritis. Curr Opin Gastroenterol 20: 592-597.

Warren JR, Marshall B (1983) Unidentified curved bacilli on gastric epithelium in active chronic gastritis. Lancet 1: 1273-1275.

Wessler S, Backert S (2008) Molecular mechanisms of epithelial-barrier disruption by Helicobacter pylori. Trends Microbiol 16: 397-405.

Yamaoka Y, Yamauchi K, Ota H, Sugiyama A, Ishizone S, Graham DY, Maruta F, Murakami M, Katsuyama T (2005) Natural history of gastric mucosal expression in Helicobacter pylori gastritis in Mongolian gerbils. Infect Immun 73: 2205-2212.

Zabaleta J, McGee DJ, Zea AH, Hernández CP, Rodriquez PC, Sierra RA, Correa P, Ochoa AC (2004) Helicobacter pylori arginase inhibits T cell proliferation and reduces the expression of the TCR zeta-chain (CD3zeta). J Immunol 173: 586-593.

Zhuang Y, Shi Y, Liu X, Zhang JY, Liu T, Fan X, Luo J, Wu C, Yu S, Chen L, Luo P, Guo G, Liu Z, Tang B, Mao XH, Guo Y, Zou QM (2011) Helicobacter pylori-infected macrophages induce Th17 cell differentiation. Immunobiology 216: 200-207. 